\title{
Reconsidering group cognition: From conceptual confusion to a boundary area between cognitive and socio-cultural perspectives?
}

\author{
Sanne Akkerman ${ }^{\mathrm{a}, 1}$, Piet Van den Bossche ${ }^{\mathrm{b}, *, 1}$, Wilfried Admiraal ${ }^{\mathrm{a}}$, \\ Wim Gijselaers ${ }^{b}$, Mien Segers ${ }^{b, c}$, Robert-Jan Simons ${ }^{a}$, Paul Kirschner ${ }^{d}$ \\ a IVLOS, Utrecht University, The Netherlands \\ ${ }^{\mathrm{b}}$ Department of Educational Research \& Development, Maastricht University, The Netherlands \\ ${ }^{\mathrm{c}}$ School of Education, University Leiden, The Netherlands \\ d Educational Technology Expertise Centre, Open Universiteit Nederland, The Netherlands
}

Received 31 March 2006; received in revised form 29 January 2007; accepted 5 February 2007

\begin{abstract}
Various strands of research in educational, social and organizational psychology focus on structures of collectively created meaning that emerge in and coordinate activities of groups. Despite expanding, this field still lacks conceptual clarity, enhanced by the multitude of terms used, such as common ground, shared understanding, collective mind, team mental models, and distributed cognition.

We conducted a review of the conceptual frameworks being used in empirical studies, focusing on the premises of the conceptualizations. Therefore, we connected these conceptualizations to either cognitive or socio-cultural perspectives on the social nature of cognition. Some studies are identified as representing initial ways of boundary crossing between these perspectives. To conclude, we explore ways for boundary crossing and cross-fertilization in future research.
\end{abstract}

(C) 2007 Elsevier Ltd. All rights reserved.

Keywords: Group; Team mental model; Collective mind; Cognitive perspective; Socio-cultural perspective

\section{Introduction}

There is a growing attention for collaboration between people. Group work has become a cornerstone of organizational life and it is increasingly being capitalized on in educational settings. Organizations rely on teams to deal with the increasingly high-demands of the environment. This is most obvious in the multi-disciplinary/-functional teams that are brought into action to deal with complex problems (Derry, DuRussel, \& O’Donnel, 1998; Hall, Stevens, \& Torralba, 2002). Fundamentally, both the working teams in organizations as the learning groups in schools are confronted with the same issues; "they are faced with challenges of establishing common frames of reference, resolving discrepancies in understanding, negotiating issues of individual and collective action, and coming to joint understanding" (Barron, 2000, pp. 403-404). Collaboration is hereby a process of building and maintaining a shared conception of a problem (Dillenbourg, Traum, \& Schneider, 1996; Roschelle, 1992). Concomitantly, studying groups and group collaboration has become an important area of research (Cohen \& Bailey, 1997). Both in educational and psychological

\footnotetext{
* Corresponding author at: Department of Educational Development \& Research, Faculty of Economics and Business Administration, University of Maastricht, P.O. BOX 616, 6200 MD Maastricht, The Netherlands. Tel.: +31 43 3883742; fax: +31 433884801.

E-mail address: piet.vandenbossche@erd.unimaas.nl (P. Van den Bossche).

1 Both authors must be considered as first authors.
} 
literature there is an identification of the need to study group learning as truly collaborative (Crook, 1998). Researchers became convinced that an individual approach will not fully grasp the phenomenon of group-work and group-learning (Thompson \& Fine, 1999). Several cognitive constructs, such as mental models, which have traditionally been considered at the individual-level of analysis, now become recognized as group-level phenomena (Klimoski \& Mohammed, 1994). In trying to grasp and understand this collaborative effort, new research interests focus on the ways groups are creating meaning and are acting upon collectively developed cognition (Thompson, 1998).

The growing interest in this group cognition can be recognized by a multitude of terms that can be found in the literature, such as common ground, team mental models, shared understanding, distributed cognition and collective mind. These terms all do refer in some way to structures of collective meaning that emerge in and coordinate the activities of a group. The idea of group cognition is proposed as a central issue in understanding (effective) group work. Group cognition is argued to provide a basis for the coordination of individual actions as well as for future communication and activity of the group (Clark \& Brennan, 1991; Hutchins, 1995). In the learning sciences it is pointed out that the development of group cognition is related to the learning potential of groups (Roschelle, 1992; Webb \& Palincsar, 1996); practices of meaning-making in the context of joint activity are at the heart of collaborative learning (Suthers, 2005; Stahl, Koschmann, \& Suthers, 2006). The development of group cognition is a process of negotiating and interrelating diverse views of group members. This process enables group members to learn from others' preferences and viewpoints by facing different viewpoints and by accepting the existence of them as legitimate (Engeström, Engeström, \& Kärkkäinen, 1995). Moreover, this process is argued to lead to rich argumentations and creative problem solutions (Homan, 2001; Matusov, 1996), as well as to the members experiencing ownership of the activity and of group products (Fiol, 1994; Mohammed \& Ringseis, 2001). The recognition of these merits made it a worthwhile endeavor for many researchers to study the processes in and through which group cognition is actually developing, potentially leading to new ways of improving group practice and group learning (Cannon-Bowers \& Salas, 2001b).

Although the research on group cognition attracts a great deal of interest and is considered to be valuable, it is confronted with some difficulties (Cannon-Bowers \& Salas, 2001b; Cannon-Bowers, Salas, \& Converse, 1993; Klimoski \& Mohammed, 1994; Matusov, 1996). In the past, some articles were published which tried to combine the conceptual developments and empirical results in fields that are concerned with the idea of group cognition (Cannon-Bowers et al., 1993; Klimoski \& Mohammed, 1994; Thompson \& Fine, 1999). These reviews acknowledge the usefulness and potential of the construct, and recognize that this is a promising line of research, but at the same time they also stress the need for more fundamental theoretical work before this potential can be realized. More specifically, they urge for theoretical integration:

(...) we have established that despite the popularity of the concept, many authors have been very casual in its application. Most disconcerting, many writers do not really define what they mean by a shared or team mental model. There is a surprising lack of definitional or conceptual clarity. Also problematic, when attempts at definition have been made, different authors have defined things in alternative (usually in incomplete) ways. In our view, part of the problem is that writers in a particular area often do not cite the literature in other areas that may be referring to the same concept of interest (albeit with a different name). To put it another way, heretofore there has not been much "cross-fertilization". Various writers seem to be "re-inventing the wheel" (Klimoski \& Mohammed, 1994, pp. 426-427)

Cannon-Bowers and Salas (2001b) have tried to describe the issues and problems the field is confronted with, and the issues on which conceptual clarity is lacking. Primarily, the literature is neither consistent in labeling nor defining concepts of group cognition. Therefore, it becomes unclear what is referred to by group cognition. We already noted that different authors use multiple terms to indicate group cognition. There are also substantial differences in the meaning of the concept. This can be illustrated by comparing the following three studies. Carley (1997) examined the "team mental model" by looking at the similarity of declarative and procedural knowledge about the task. A different study is that of Levesque, Wilson, and Wholey (2001), who examined under the label "shared mental model" the similarity of cognition about the team processes and expertise in the team. Yet another study of Yoo and Kanawattanachai (2001) focused on the 'collective mind' of groups, hereby referring to the social cognitive system in which individuals heedfully interrelate their actions. Besides the use of different terms and meanings, sometimes the same terms are used with different meanings. For example, Matusov (1996) argues that traditionally "intersubjectivity" is studied with a focus on processes of unification of the participants' subjectivities, while he pleads for a focus on how participants coordinate their contributions in the joint activity. A different definition of intersubjectivity lies behind these various approaches. 
Cannon-Bowers and Salas (2001b) warn that clear statements of what group cognition is and how it operates become impossible as long as there is conceptual confusion. One of the problems emerging from this is the usage of very distinct measurement approaches in different studies. For example, whereas Levesque et al. (2001) and Carley (1997) measure mental models of individuals and try to compute some kind of similarity as indicator for group cognition, Yoo and Kanawattanachai (2001) ask the team to evaluate the interrelations of the actions in the team as a whole and use this as an indicator.

The lack of clarity encountered in this area of research, makes it difficult to make use of and build forward on the various empirical studies, since it is unclear how the empirical studies relate to each other as they use many different concepts as well as different, but often implicit, understandings of group cognition. Both the research on group cognition and the practice of groups and group learning, or the optimization of this practice, would benefit from an awareness of the different conceptualizations being used. This would encourage future research to build upon previous results and could deliver guidelines for both conceptualizing the object of study and choosing research methodologies. It opens the possibility to compare the evidence gathered, potentially leading to more general conclusions, and building a ground for new questions and approaches.

The purpose of this review is to analyze the different conceptualizations of the construct group cognition by looking at the premises of the various conceptualizations. Instead of making a comparative inventory of concepts related to the construct of group cognition and their definitions, we aim to go beyond these concepts and definitions by pointing out differences and similarities in how the construct of group cognition is conceptualized in the empirical literature in educational and psychological sciences. By typifying the various conceptualizations we aim to lay the ground for conceptual clarity that enables to build on each other's work. This conceptual review is not intended to provide a complete and final overview of empirical studies on group cognition nor present the specific findings. Rather, the review is meant to cover and structure the broad range of conceptualizations. The emphasis is on a dialectic re-conceptualization of the existing diverse terminology, and the identification of the conflicting premises and methodologies.

We will present a framework that we found to reveal the important dimensions on which these conceptualizations differ from each other. This framework draws on two socio-genetic views, representing two different ideas about the social nature of cognition. How one understands the social nature of cognition is fundamental for conceptualizing group cognition. Therefore, this framework was found to be of value to map the types of conceptualizations of group cognition that are found in the empirical literature.

The plan for this review is as follows. In the next section, we will first elaborate on the framework in which we distinguish cognitive and socio-cultural perspectives. This will be followed by a method-section in which we describe how we used this framework to analyze the differences in conceptualizations that are present in the empirical literature. Next, we will present the results of this analysis. We found that the studies on group cognition can be categorized into three types of conceptualizations of group cognition. Hence, in the results section these three groups of studies are discussed, respectively illustrating understandings of group cognition according to cognitive perspectives, sociocultural perspectives, and those that seem to be on the boundary between these perspectives. We will characterize each group of studies by showing how group cognition is being addressed, both conceptually and operationally. We will end up by looking at the value of these different types of conceptualizations and questioning how they complement each other. Finally, we will explore how to reach more cross-fertilization in future research.

\section{Two socio-genetic views: cognitive and socio-cultural perspectives}

In our process of analyzing the literature on group cognition, we noticed an essential difference in the conceptualizations that relates to a more fundamental distinction in the way one perceives the social nature of cognition. To address the question of how to frame the diversity of conceptualizations of group cognition, this article draws on Valsiner and Van der Veer (2000), who clearly identified and distinguished two socio-genetic views, one underlying cognitive and one underlying socio-cultural perspectives which entail basically different ideas about the social nature of cognition. In order to further analyze the conceptualizations of group cognition and explicate the differences, we used these socio-genetic views as initial framework for the analysis. Before turning to the actual analysis, we will elaborate on these views and build the framework we used for our interpretations. In building our framework, we integrated literature in general educational and psychological theorizing that closely relates to the socio-genetic views presented by Valsiner and Van der Veer, and that points to the controversy between the socio-genetic views. 
In educational and psychological theorizing an individualistic approach towards the human mind was, and perhaps still is, dominant. This approach has been questioned for its lack of providing a meaningful account of social interactions (Thompson, 1998). At present, most social scientists seem to acknowledge that human psychological functions stand in close relationship with the social environment in which they are situated (Valsiner \& Van der Veer, 2000). As such, individual learning and development is studied as involving social aspects (Salomon \& Perkins, 1998). Through acknowledging the importance of the social practices in which the individual is engaged, the dispute is no longer about the appropriateness of the individual versus the social collective as unit of analysis (Cobb \& Bowers, 1999). Rather, there is confusion about how the actual relation between the person and the social should be conceptualized. Valsiner and Van der Veer distinguished two socio-genetic views that theorize this relation differently. They state "there is the axiomatic preference for fusion (of person and the social environment) or inclusive separation (i.e., the person is viewed as distinguished from the environment, yet interdependent with it) bases for socio-genetic models" (p. 6). Whereas the former socio-genetic view perceives the person and the social environment as one whole and relies on terms like participation and adaptation, the latter socio-genetic view perceives the person and the social environment as separate units that are related to each other and uses terms such as internalization and externalization. Sfard (1998) notes a similar distinction of perspectives when she describes two different learning metaphors. The first, more traditional metaphor being used is the acquisition metaphor, wherein learning is seen as acquiring knowledge. The subject of learning is the individual who acquires knowledge about the world surrounding him/her. A learning theory that is based on this metaphor is cognitivism. The second metaphor is the participation metaphor, wherein learning is seen as a process of becoming participant in a community. The learner is then also seen as a participant, and knowledge is rather an aspect of discourse and activity. Knowledge is preferably referred to as "knowing". This metaphor is said to be related to socio-cultural views of learning. Socio-cultural views emphasize the social, cultural, historical and situative nature of cognition and activity, and are grounded in traditions of Vygotsky (1978), Mead (1934), Bakhtin (1981, 1986), Luria (1976) and Leontev (1978). Salomon and Perkins (1998) noted that the different ways of understanding social contributions to learning are the result from different ideas about where information processes lie (within the individual mind versus within social interaction) and about what entity these processes serve (the individual or a social entity). It is the first dimension, where information processes lie, that distinguishes the two socio-genetic views. Combining these distinctions, the one view on socio-genesis is the "inclusive separation" view, which is related to the "acquisition metaphor" and connected to "learning within the mind". The other view on socio-genesis is the "fusion" view, which is related to the "participation metaphor" and connected to "learning within social interaction".

These two socio-genetic views also lay behind a previous discussion between researchers from the cognitive perspective and those from the situated perspectives as found in psychological theories (Anderson, Reder, \& Simon, 1996, 1997; Cobb \& Bowers, 1999; Greeno, 1997). Also, several attempts have been made to create initial bridges between the two perspectives (Billet, 1996; Gauvain, 2004; Glick, 2004; Greeno, 1998; Saxe \& Simonde, 2004). In order to arrive at a framework for our review, we have scrutinized how the various authors characterized and positioned the socio-genetic views, and determined what distinctive conceptual dimensions are associated with them. The results are summarized in Table 1.

In this article, we have chosen to use the general term "cognitive perspectives" which is associated to the inclusive separation view of socio-genesis and in a general sense the term "socio-cultural perspectives" to refer to the fusion view of socio-genesis.

As pointed out in Table 1, an essential difference between the two socio-genetic views is encapsulated in the understanding of the individual. In the one view, underlying cognitive perspectives, the individual is seen as an autonomous agent, an active person who constructs personal understanding of the world surrounding him or her. This understanding is reflected in a mental network of internal constructs of meaning stored in memory. The social world surrounding the individual is seen as a set of social contexts in which the person acts. These contexts are considered important and although complex, can be analyzed through its components. The individual moves through these contexts, responds to them and is affected by them. These notions indicate that the social is certainly not denied by these perspectives, but that the social is understood through its residence in the mind of the individual.

In the fusion view of socio-genesis, underlying the socio-cultural perspectives, the individual is seen as a participant in social practices, in which he/she is interacting with others and with material and representational systems. Participating in social and cultural practices contributes to the construction of the participants' dispositions to agree with certain propositions or routine practices, and as such to his or her identity. The socio-cultural perspectives do not deny the 
Table 1

Socio-genetic views: Cognitive and socio-cultural perspectives

\begin{tabular}{|c|c|c|}
\hline Distinctive conceptual dimensions & $\begin{array}{l}\text { Cognitive perspectives } \\
\text { "Inclusive separation" socio-genesis (Valsiner \& } \\
\text { Van der Veer, 2000) }\end{array}$ & $\begin{array}{l}\text { Socio-cultural perspectives } \\
\text { "Fusion" socio-genesis (Valsiner \& Van der Veer, } \\
\text { 2000) }\end{array}$ \\
\hline The individual & Individual as autonomous; promotes individuality & $\begin{array}{l}\text { Individual as participant; absorbs the individual in } \\
\text { social practices }\end{array}$ \\
\hline The social world & Contexts of performance & $\begin{array}{l}\text { Evolving systems of socially organized discourse } \\
\text { and activity }\end{array}$ \\
\hline Individual-social & $\begin{array}{l}\text { Individual actions can be independent of social } \\
\text { structures or interactions }\end{array}$ & $\begin{array}{l}\text { All individual activity involves socially organized } \\
\text { activity }\end{array}$ \\
\hline Cognition & $\begin{array}{l}\text { Individually constructed structures in memory } \\
\text { consisting of conceptual and procedural knowledge }\end{array}$ & $\begin{array}{l}\text { Dispositions to agree with certain propositions being } \\
\text { culturally shaped and patterned by social and } \\
\text { cultural circumstances }\end{array}$ \\
\hline Learner & (Re-)constructor & Peripheral participant, apprentice \\
\hline Learning & Entails gaining possession over some commodity & $\begin{array}{l}\text { Entails contribution to an individual's identity as } \\
\text { valuable participant in social practices }\end{array}$ \\
\hline Knowledge & $\begin{array}{l}\text { is considered a structure in the person's mind, and as } \\
\text { such a property, possession, or commodity of the } \\
\text { individual }\end{array}$ & $\begin{array}{l}\text { is considered as knowing, and as such an aspect of } \\
\text { discourse and activity }\end{array}$ \\
\hline Key terms & $\begin{array}{l}\text { knowledge, concepts, notions, meaning, sense, } \\
\text { schema, representation, reception, acquisition, } \\
\text { construction, internalisation, transmission }\end{array}$ & $\begin{array}{l}\text { knowing, practice, activity, discourse, } \\
\text { communication, social mediation, participation, } \\
\text { belonging, situatedness, contextuality, cultural } \\
\text { embeddedness }\end{array}$ \\
\hline
\end{tabular}

existence of an individuals' mind, nor its agency, but they understand this mind as situated in the participation processes in systems of socially organized activity that are themselves evolving.

Research on group cognition can be identified that seems to be starting from either a cognitive or a socio-cultural perspective. However, although representing two fundamentally different socio-genetic views, this is rarely made explicit. As these socio-genetic views both convey a specific understanding of the social nature of cognition, they both can be considered relevant for conceptualizing group cognition. To understand the concept of group cognition, one has to deal with what is meant by cognition as well as what is meant by cognition at a group-level. This entails defining cognition (where does it reside?) and defining cognition in terms of individual and social dimensions (how are they related?). For that reason, we will use the framework presented in Table 1 to outline the important dimensions on which the conceptualizations of group cognition in empirical studies differ. Hereby, we reach beyond the definition given by authors and try to disclose their premises regarding socio-genetic views.

\section{Method}

\subsection{Literature search}

The goal of the literature search was to gather a representative sample of the multiplicity of conceptualizations of group cognition. Hereto, the search was based on a variety of terms that refer to group cognition. Based on the conceptualizations in theoretical literature (e.g., Cannon-Bowers \& Salas, 2001b; Klimoski \& Mohammed, 1994) and our first readings of empirical studies, we composed a list of synonyms, looking initially at all combinations of:

o Words implying cognition: capital, cognition, frame of reference, framework, ground, intersubjectivity, meaning, mental model, mind, perspective, position, representation, thinking, understanding, view, vision, voice;

o Words referring to the aspect of group: collective, common, distributed, group, joint, mutual, shared, social, team.

In the search, these terms were always combined with the search terms "group" or "team". ${ }^{2}$ Two major computerized databases were screened: The Educational Resources Information Centre (ERIC) catalogue and PsycLIT. These

\footnotetext{
${ }^{2}$ Some combinations already included the term group or team, for example 'group cognition' or 'team mental models'. In the other combinations it was necessary to limit the search to those studies that were looking at group level.
} 
databases give access to materials from the educational and psychological sciences, but also from related disciplines such as organizational behavior, medicine, social work, law and criminology. We did not limit the search in time, nor in source of publication.

A first selection of the studies was based on the abstracts; in a next step also the complete articles were screened. Those studies were selected which had group cognition as a central object of study (we were not interested in studies that only marginally touched upon the idea) and they had to study this idea at the group-level (some studies consider this idea at for example organizational level). Furthermore, we were primarily interested in empirical studies on group cognition (a lot of studies mention group cognition terms but do not study it as such). The reason for focusing on empirical studies was that we wanted to reach an in-depth understanding of how the author conceptualized the idea of group cognition. Therefore, we did not only focus on the explicit meaning attributed to the concept of group cognition by the author as shown in the theoretical background and definitions of the concept, but also on the meaning-as-used by the author. The latter is best shown in the research methodology being used to measure the concept in the empirical part of the studies. Although non-empirical work was taken into account for the development of the theoretical framework, this work was not included in the analysis. This resulted in 22 studies. $^{3}$ These 22 studies formed the basis for further analysis. Though this is a small amount of studies, on the basis of systematically scrutinizing the literature we believe they cover and demonstrate the diverse conceptualizations of group cognition.

\subsection{Analyzing the literature}

We summarized the studies we selected based on a range of characteristics (study aim, theoretical assumptions, concept used for and definition of group cognition, study design, group characteristics, task of the group, time, method of analysis, measurement of group cognition, antecedents and consequences of group cognition and the subsequent analysis, conclusions of the study). This resulted in a table of review used as a tool for further analysis.

Our analysis aimed to question in what respects these conceptualizations differ, using the socio-genetic views as framework. First, studies were categorized as representing a cognitive or a socio-cultural view on group cognition. This categorization was a result of the conceptual dimensions in Table 1, and determined holistically whether the theoretical framework of the study represented more the cognitive or the socio-cultural perspectives. The first two authors of this paper were concerned with categorizing the studies. In most cases, both authors came to the same categorization. The few cases of doubt were resolved after discussion. This resulted in 11 studies representing cognitive perspectives, 5 studies representing socio-cultural perspectives, and 4 studies having characteristics of both socio-genetic perspectives. These latter studies were classified as "boundary crossing studies". Two studies (Hare \& O'Neill, 2000; Mulder, Swaak, \& Kessels, 2002) were found that did not define or conceptualize, nor offered more implicit understandings of the concept in the theoretical introduction. They did not analyze group cognition itself, but group member's perception of the development of group cognition. Because no conceptualizations could be derived from these studies, they were excluded from further analysis.

After categorizing the studies, we analyzed them and focused on the socio-genetic issues "where cognition resides" (how is cognition conceptualized), and "how the individual and the social relate" (how is cognition conceptualized at group-level). We will discuss how the different studies in the discerned groups of cognitive perspectives, socio-cultural perspectives and boundary crossing studies dealt with these two questions. In addition to this categorized description, the Appendix A provides an overview of each individual study (i.e., the conceptualization and analysis of the group cognition-construct).

\footnotetext{
${ }^{3}$ Of the 984 abstracts that we found with the search, 167 studies were selected which referred to group cognition terms as one of the central concepts in the study. Of those, 120 abstracts studied cognition at group level. Only 70 abstracts referred to an empirical study. Of those, we were able to find 29 studies (As we did not limit the search to time or source, several studies were not traceable despite contacting the authors. These non-traceable studies concerned 7 conference papers and 15 dissertations. Additionally, 2 publications appeared to be non-English literature and were not included. Also, 1 book, 4 chapters in a book, 9 articles and 3 manuscripts published by an organisation were non-retraceable, some of them because they were published more then 15 years ago.), of which 22 studies indeed concerned empirical studies with group cognition as object of study.
} 


\section{Overview of the empirical studies on group cognition}

\subsection{Cognition}

First, we explicitly looked at the diverse interpretations of cognition, referring not only to the kind of asset or quality that group cognition entails, but simultaneously where this particular asset or quality is considered to be localized. Second, we describe how the groups of studies analyzed cognition. We will respectively discuss studies reflecting cognitive perspectives, socio-cultural perspectives and those that reflect both perspectives (the boundary crossing studies).

\subsubsection{Cognitive perspectives}

As for the conceptualization of cognition, the studies connected to the cognitive perspectives refer to the knowledge of the individual team members. More specifically, these studies rely mostly on the construct of mental models (Klimoski \& Mohammed, 1994). This construct assumes that individual people organize knowledge into structured, meaningful patterns and store them in their memory (Johnson-Laird, 1983; Rouse \& Morris, 1986). Some of the authors (Druskat \& Pescosolido, 2002; Edelson, 2000; Levesque et al., 2001; Mathieu, Heffner, Goodwin, Salas, \& Cannon-Bowers, 2000; Peterson, Mitchell, Thompson, \& Burr, 2000) point out how these mental model function, hereby showing the crucial importance of this construct for understanding (team) performance. Reference is often made to the definition offered by Rouse and Morris (1986): "mechanisms whereby humans generate descriptions of system purpose and form, explanations of system functioning and observed system states, and predictions of future system states" (p. 360). Mental models enable team members to form accurate explanations of and expectations for their environment (Levesque et al., 2001), and in turn allow them to coordinate their actions and adapt their behavior to demands of the environment (Cannon-Bowers et al., 1993).

There are several types of mental models, containing different kinds of content. Each of these different types of models is considered to be relevant for the functioning of teams (Cannon-Bowers et al., 1993; Klimoski \& Mohammed, 1994; Mathieu et al., 2000; Rentsch \& Hall, 1994). The most elaborated categorization of the types of mental models and their knowledge content is proposed by Cannon-Bowers et al. (1993). They discern four types of mental models that can be shared in teams:

o Task model (e.g., group cognition regarding task strategies, environmental constraints);

o Team interaction model (e.g., group cognition regarding interactions patterns, roles/responsibilities);

o Team model (e.g., group cognition in terms of awareness of team-mates' knowledge, skills);

o Equipment model (e.g., group cognition regarding a shared idea about equipment functioning, operating procedures).

As indicated in Table 2, the studies reviewed primarily focus on task and/or team interaction as the type of mental model. Only Levesque et al. (2001) did also study the mental models of team members about each other's expertise (team model). None of the studies considered the equipment model.

The analysis of the studies from a methodological perspective indicates that two different aspects of the mental models as a knowledge structure are considered: (1) the content aspect or the possession of certain knowledge, and (2) the structural aspects or the specific way the knowledge base is structured. Therefore, in trying to understand the individual mental model, the literature (e.g., Langan-Fox, Code, \& Langfield-Smith, 2000; Mohammed \& Dumville, 2001) claims that two issues need to be taken into consideration. One is elicitation; a procedure used to ascertain the content of the mental model. The other issue is representation; a procedure used to determine the relation between the content elements or the structure of the mental model.

A part of the analyzed studies (see Table 2) elicit the mental model content using Likert-scale questionnaires (Edelson, 2000; Ensley \& Pearce, 2001; Levesque et al., 2001; Mohammed \& Ringseis, 2001; Peterson et al., 2000). Hereby, these studies did not look at the representation or structure of the mental models. The other studies look at both elicitation as well as representation of the mental models, using three different kinds of techniques. One technique being used is relatedness ratings (Marks, Burke, Sabella, \& Zaccaro, 2002; Mathieu et al., 2000; Langan-Fox, Wirth, Code, Langfield-Smith, \& Wirth, 2001; Stout, Cannon-Bowers, Salas, \& Milanovich, 1999). In this technique individual team members are asked to judge the relatedness of concepts provided by the researcher. This information is then used by most authors (except for Langan-Fox et al., 2001) as input for the analysis, using programs as Pathfinder and UCINET. This allows for generating each group member's mental model. Concepts that are highly related to one another are 
Table 2

Characteristics of the studies in cognitive and socio-cultural perspectives, and studies that cross the boundary

\begin{tabular}{|c|c|c|c|c|c|}
\hline & Cognition interpretation & Measurement & $\begin{array}{l}\text { Group cognition } \\
\text { interpretation }\end{array}$ & Measurement & $\begin{array}{l}\text { Role of group cognition in } \\
\text { relation to group processes \& } \\
\text { outcomes }\end{array}$ \\
\hline \multirow[t]{3}{*}{ Cognitive perspective } & $\begin{array}{l}\text { - Individual task mental } \\
\text { model }(4,6,8,9,14,18,19 \text {, } \\
20)\end{array}$ & Quantitative analysis: & $\begin{array}{l}\text { Similarity/overlap between } \\
\text { individual mental models }(3 \text {, } \\
4,6,8,9,13,14,19,20,21)\end{array}$ & $\begin{array}{c}\text { - Aggregation measurement } \\
(3,4,6,8,9,13,14,20,21)\end{array}$ & - Input $(6,19,20)$ \\
\hline & $\begin{array}{l}\text { - Individual team interaction } \\
\text { mental model }(3,4,6,8,13 \text {, } \\
\text { 21) }\end{array}$ & $\begin{array}{l}\text { - Relatedness ratings }(6,13 \text {, } \\
19,20)\end{array}$ & & - Global measurement (18) & - Process $(3,8,9,14,21)$ \\
\hline & & $\begin{array}{l}\text { - Likert-scale questionnaires } \\
(3,4,8,9,21) \\
\text { - Concept mapping (19) } \\
\text { - cognitive mapping (14) } \\
\text { - discourse and activity (18) }\end{array}$ & & & - Output $(4,13,18)$ \\
\hline \multirow[t]{3}{*}{ Socio-cultural perspective } & $\begin{array}{l}\text { - Process of defining the } \\
\text { object of activity (task model) } \\
(5,11,16,17,22)\end{array}$ & Qualitative analysis: & $\begin{array}{l}\text { Cognition constituted by the } \\
\text { group within social } \\
\text { interaction }(5,11,16,17,22)\end{array}$ & $\begin{array}{l}\text { Global measurement }(5,11 \text {, } \\
16,17,22)\end{array}$ & - Common ground $(5,17)$ \\
\hline & $\begin{array}{l}\text { - Process of defining the roles } \\
\text { and responsibilities (team } \\
\text { interaction model) (22) }\end{array}$ & $\begin{array}{l}\text { - Discourse and activity }(5, \\
16,17,22)\end{array}$ & & & $\begin{array}{l}\text { - Common engagement }(5, \\
11,16,22)\end{array}$ \\
\hline & & - Group reports (11) & & & $\begin{array}{l}\text { - Updated common ground } \\
\text { (5) }\end{array}$ \\
\hline \multirow[t]{2}{*}{ Boundary crossing } & Task model $(1,2,7)$ & $\begin{array}{l}\text { - Qualitative analysis of group } \\
\text { discourse and activity }(2,7)\end{array}$ & Distributed $(1,2,7)$ & Global measurement $(1,2,7)$ & - Input $(1,7)$ \\
\hline & & $\begin{array}{l}\text { - Quantitative analysis of } \\
\text { self-assessment (1) }\end{array}$ & & & - Process $(1,2,7)$ \\
\hline
\end{tabular}

Note: numbers refer to the numbers of the studies presented in Appendix A. 
more closely linked within the structure (Kraiger, Salas, \& Cannon-Bowers, 1993). A second technique used is concept mapping (Marks et al., 2002), in which participants are asked to choose from a range of concepts and place them in a pre-specified hierarchical structure. A third technique, used in one of the studies (Carley, 1997), is that of using idiosyncratic information of the team members. In this particular study the participants responded essay questions. The resultant texts are supposed to contain a portion of the author's mental model at the time the text was created (Kaufer \& Carley, 1993). An automated approach of the cognitive mapping technique was used to extract the concepts and the relations between these concepts out of these texts. This resulted in a map, a network of concepts that was considered as an elicitation and representation of the individual's mental models (Carley, 1997). The difficulty of the first two techniques is that the concepts relevant to the team or task are specified in advance by the researcher (based on other sources such as task analysis, experts, existing scales, etc.), which may not match the participants' knowledge structures (Mohammed, Klimoski, \& Rentsch, 2000). This drawback can be countered by the third technique of capturing the idiosyncratic content of an individual's knowledge structure. However, in this latter technique it can be difficult to compare different individual mental models (Mohammed et al., 2000).

Unlike the other studies, O'Neill, Johnson, and Johnson (1999) did not rely on a direct measurement of the "internal private model", but state that "the evidence that is available (...) on which that inference may be based is the verbal and nonverbal communications that [is presented] through their interaction" (p. 69). This shows how they infer the mental model of the individuals based on the verbal and non-verbal communications.

\subsubsection{Social-cultural perspectives}

As for the conceptualization of mind, the studies related to the socio-cultural perspective refer to contributions in the activity, focusing on the actions that the group participants undertake during the group work (see Table 2). All five studies related to the socio-cultural perspective were concerned with the question how the group participants acted on, and thereby defined the specific domain or object of activity. In other words, this domain is what motivates the people to work together, and through working together they define concretely this particular domain. The process of defining the domain or object of the work can be regarded as a continuous process of creating, what in cognitive perspectives would be called "task models". In these studies, defining the object of activity, or creating a task model, is considered to be important for the purpose of understanding a certain problem or question, coordinating actions, and ultimately achieving the goal of the activity. For example, Granados (2000) studied the group understanding of the design space or conceptual structure that is build by a group of students, by analyzing the commands in performing the task and the kinds of marks (clarifying statements and questions) that are made within the group. De Haan (2001) was concerned not only with how pairs defined the object of activity (the task model), but also with the so-called "team interaction model" that the pairs were using, by looking at the way teacher-pupil and parent-child pairs divided roles and responsibilities in solving a particular task. In these five studies, "mind" is closely related to how one participates in or contributes to the immediate joint activity (Matusov, 1996), in this case the specific task at hand. Additionally, the studies were concerned with cultural dimensions of cognition. Some studies (Auer-Rizzi \& Berry, 2000; De Haan, 2001; Hall et al., 2002) addressed how participants coming from similar national cultures, disciplines or professions, use also similar ways of talking and express their own way of understanding the situation at hand. But this cultural dimension of cognition is also salient in how these studies do look at joint activity itself, since they focus on how the specific ways of talking and understanding of the diverse participants contribute to the development of a group culture.

In line with conceptualizing 'cognition' as situated in the activity of the group, the five studies focus their analysis on group discourse and activity (see Table 2). Four studies (Auer-Rizzi \& Berry, 2000; De Haan, 2001; Hall et al., 2002; Granados, 2000) focused not only on the content of what is being discussed in groups (about the object), but also on the way the group interacts. For example, De Haan conducted first a qualitative analysis of the organizational structure of the interactions and of the role divisions that were set up, using a checklist of open questions. Secondly, she studied the specific pattern of participation structures and control strategies by a task analysis of subtasks scoring video's of the activity on: who is taking the initiative, to whom is it directed, who performs, and what is the involvement of the non-performing partner. These four studies all argued that the framing of expressions also indicates how one understands the task or object. Only Fiol (1994) did not directly analyze the group discourse, but followed the two year collaboration process of a new-venture team by analyzing the written reports made by the team. In several studies coding techniques were used with codes based on either theory (Fiol, 1994) or preliminary analysis (Granados, 2000; De Haan, 2001). In analyzing the discourse and activity of the group, the studies 
were not focused on determining the individual cognitions of each group member. Rather, they focused on group cognition, as implied by the whole of contributions that the group participants made during the interactions and actions.

\subsubsection{Boundary crossing}

We found three studies (Derry et al., 1998; Banks \& Millward, 2000; Yoo \& Kanawattanachai, 2001) that we consider to be boundary crossing literature, because they were able to pursue a mixed discourse of both cognitive as well as socio-cultural perspectives on mind throughout the whole study (see Table 2). These three studies focus both on a stable cognitive map (or memory structure representing information and form), and on dynamic, situated cognitions representing coordination of information and actions. Derry et al. distinguished the individual long-term memories and the thoughts shared by the individuals during the group work. Similarly, Banks and Millward (2000) made a distinction between on the one hand a mental model form, representing a map of elements and their relations and on the other hand mental model states, representing the dynamic configuration of the aspects of the model that can be changed when running the model. Yoo and Kanawattanachai (2001) distinguished transactive memory, referring to information that is encoded, stored, and retrieved from the memory of the individual members and the individual minds at work during group activity. These three studies were all concerned with the ideas and information in the teams relevant for conducting the task, or task models, and how these were created in the teams.

The three studies used different methodologies (see Table 2). Derry et al. (1998) used discourse analysis of the interactions, to determine if the list of ideas resulting from the meeting represented cognitions that have been more or less processed by group discussions. Banks and Millward (2000) coded all the communication used and the actions taken with respect to mental model forms and mental model states. For example, one of the categories used is "offers"; these kinds of communications provide information about the model form. Yoo and Kanawattanachai (2001) used self-assessment, asking the group participants to fill in a questionnaire with items referring to the amount of transactive memory and of collective mind. This questionnaire asked for the perception of behavioral attributes of the team. Based on these, inference is made regarding the cognitive constructs of transactive memory and collective mind.

The fourth study of Rutkowski and Smits (2001) that was initially classified as boundary crossing, seemingly connected to both perspectives, and mixed the two socio-genetic views in discussing group cognition. However, close examination of the study revealed that it did not enlighten the issue of boundary crossing. Rutkowski and Smits claim to look at two schools of thought, constructivist and constructionist schools, similar to what we have termed respectively the cognitive and socio-cultural perspectives. But, because of the separate "treatment" of the two theoretical schools, we do not regard this study as a boundary crossing study, even though they explicitly mention and discuss the two schools of thought related to the concept of shared meaning.

\section{2. 'Group' cognition}

We have described how the studies considered cognition, that is, how they defined and analyzed it. We will now turn to the conceptualizations of cognition at the group-level in these three groups of studies (studies reflecting cognitive perspectives, socio-cultural perspectives and studies that reflect both). We first elaborate on the diverse interpretations of the meaning of cognition at group-level in the studies. Second, we describe how the groups of studies measured cognition at group-level. Therefore, according to Mohammed, Klimoski, and Rentsch (2000), we distinguish between two ways for measuring group-level cognitive structures. Individual measures can be aggregated to create higher level measures (aggregated measurement), or the collectivity can speak for itself (global measurement) (Axelrod, 1976; Schneider \& Angelmar, 1993). Third, we describe how the groups of studies perceived the role of group cognition in relation to group processes and outcomes.

\subsubsection{Cognitive perspectives}

Cannon-Bowers and Salas (2001b) provide an overview of four interpretations that are outlined in the literature pertaining to the cognitive perspective (Cooke, Salas, Cannon-Bowers, \& Stout, 2000; Mohammed \& Dumville, 2001; Cannon-Bowers et al., 1993). The first refers to "overlap" of the individual cognitions: team members have a part of their knowledge base that is communal. In the second, the authors interpret group cognition as 'similar' or 'identical' between the team members: they hold identical knowledge. In the third 
group cognition is considered as 'complementary': knowledge or team-members does not need to be identical, but leads to the same expectations for the task at hand. In the fourth, group cognition is conceptualized in terms of 'distributed': the knowledge necessary for the task is dispersed among the different members of the group.

As indicated in Table 2, all studies from cognitive perspectives conceptualize group cognition as a similarity or overlap between individual mental structures. They are interested in the communality of the cognitions between team members. Cannon-Bowers and Salas (2001a) refer to this group of studies as literature on shared cognition and define them as follows: "They all encompass the notion that team members hold some knowledge that is similar or overlapping" (p. 87). Group cognition is conceptualized as a group-level construct, but therefore they rely heavily on the individual as entity. To share becomes nothing more than a cross-section of those individual entities. And 'what' they share reflects organized knowledge; individuals store concepts and relations between these concepts. Group cognition is defined in terms of similarity in these concepts and relations. What underlies this conceptualization is that cognition is housed in the mind, as an individual possession. This is also reflected in the use of concepts that are derived from cognitive psychology conceptualizing individual cognition.

Most studies use the phrase 'similarity' in their definition of group cognition. For example, Mohammed and Ringseis (2001) define the idea of group cognition as similarity among group members regarding how key matters are conceptualized. Others rely on other terms like convergence or overlap; for example Mathieu et al. (2000) define shared mental models as the convergence of individual mental models. Nevertheless, the methodology in all studies shows a focus on similarity, with the underlying hypothesis that the more similarity in the identified knowledge structures of the individuals, the better the team functions. Also Mathieu et al. compute a correlation between matrices of individual ratings and relate this to better team processes and performance.

Following this line, almost all studies rely on aggregated data to represent this group-level construct (see Table 2). This aggregation is measured by calculating either the variance or the similarity of individual measures (comparing individual questionnaire answers or individuals' cognitive maps). For example, some calculated the average of pair wise comparisons between members (Peterson et al., 2000; Edelson, 2000). Carley (1997) relied on the individual idiosyncratic cognitive maps to determine the team mental model. Hereby, a thesaurus is used to decide if the content of individual mental models is similar or not. Only the study of O'Neill et al. (1999) does not make use of data aggregation. They use, what Mohammed et al. (2000) call, a global measurement technique; the researcher does not integrate the cognitive structures, but instead the group cognition is elicited from a key informant, observing group interaction or examining group products. O'Neill et al. used representations of the group members, video records of participants, and insights gained from the author's involvement as a participant-observer and from interviews and conversations.

Although all studies show a similar conceptualization of group cognition in terms of what is meant by "shared", they use different hypotheses about the role of group cognition in relation to group processes and outcomes (see Table 2). First, one can look at group cognition as input for teams to start working (input), as mediating for team performance (process), or as result in itself (output). Most of the studies study the role of group cognition as a result of team processes. The studies of Langan-Fox et al. (2001), Levesque et al. (2001) and O'Neill et al. (1999) are focused on the development of group cognition as a result in itself (output). Langan-Fox et al. (2001) and Levesque et al. argue that the development of group cognition is important because it supports a group to work, as it enables individuals to adapt their behavior to the task and other team members. A range of other studies also picture group cognition as a result of group processes, but in addition study whether group cognition is related to (a) the successfulness of the group (Carley, 1997; Edelson, 2000; Peterson et al., 2000); (b) the perception of implementation success (Mohammed \& Ringseis, 2001), or (c) the performance of the firm (Ensley \& Pearce, 2001) (process). For example, Ensley and Pearce study, among several other relations, whether the extent to which mental models on strategy are shared between teams, is related to the success of the firm in terms of sales growth.

In contrast to these studies, three studies (Marks et al., 2002; Mathieu et al., 2000; Stout et al., 1999) examined the influence of group cognition on subsequent group processes (input). Hereby they depicted the role of group cognition as an input variable. Stout et al. and Mathieu et al. delivered training to their participants, by way of establishing group cognition as a starting condition for the real teamwork. Marks et al. did not use a training period in their design, but allowed a planning period in a kind of pre-performance period. In these three studies, group cognition is treated as an input variable for further group-work. 


\subsubsection{Socio-cultural perspectives}

As indicated before, the studies in the socio-cultural perspectives defined cognition in terms of contributions to joint activity. Furthermore, these studies consider group cognition as constituted by the way in which those contributions have a central orientation towards defining the object of activity. If a group shows a particular pattern in defining the task at hand, then that pattern is indicative for the group cognition. The studies of the cognitive perspectives showed diverse interpretations of group cognition. Unlike the cognitive perspectives, the socio-cultural perspectives do not interpret cognition at the group-level in terms of similarity, overlap, complementarity, or distribution. All these four interpretations imply some sort of comparison between separate individual minds. The socio-cultural perspective rather perceives group cognition as something constituted by the group as an entity in itself. As such, cognition resides in the active mind, as a phenomenon situated in the group interaction. The concept group cognition is then defined as a process of coordination of participants' contributions in joint activity (Matusov, 1996). Despite different contexts, the studies all define group cognition as a process phenomenon that is situated in group collaboration and that allows for coordinated action (see Table 2). Similar to this focus on coordinated action is the concept of collective mind as described by Weick and Roberts (1993). They described and illustrated collective mind in organizations as a pattern of heedful interrelations of actions in a social system. In such a pattern, actions are conscientiously, critically and carefully (i.e., heedful) constructed. Moreover, when actions are constructed, the acting subject envisages the social system of joint actions, and subordinates his or her actions to this system (interrelate). Additionally, Matusov notes how a "participatory notion of intersubjectivity" (cfr. socio-cultural perspective on group cognition) moves beyond individual intentionality, since the direction of the activity is not foreseen by any of the participants. In these studies, "shared" refers to the degree of coordination that is seen in this social action. When contributions in the group have a central orientation, it is possible to coordinate the actions, even though the participants may have diverse views or even disagreements. For example, Granados (2000) talks about how the group, working on a design problem, develops a design space, which is an "open and negotiated conceptual structure that contains the ongoing collective specifications relevant to the design activity" (p. 505). Moreover, using similar modes of thinking is argued to lead to reproductive processes, with the danger of group think narrowness, while disruptions resulting from different views of participants and socio-cultural subgroups are perceived as offering potential for productive, creative processes and group development (Homan, 2001; Matusov, 1996).

The five studies measure group cognition by looking what patterns are revealed in their analysis of the group interaction and work (see Table 2). Thereby they used "global measurement". The patterns within the group's interaction and work show how the participants coordinate their actions and arrive at a decision or solution to the problem. So far as these studies do look at individual cognitions and compare them, these studies always focus on cognition as it appears during social interaction. However, the focus is not on a set of individual minds, but on the mind that is established by the whole group or by socio-cultural subgroups, as directly implied by the patterns in the interaction. For example, Hall et al. (2002) analyze how disciplinary groups put their difference in understanding and in using objects into coordinated action and when these differences lead to conflict.

Similar to the studies showing cognitive perspectives, these five studies also have different understandings of the role of group cognition in relation to group processes and outcomes (see Table 2). However, whereas the studies in the cognitive perspectives differed in conceptualizing group cognition as either input, process of output variable, the model of input-process-output variables does not apply to these five studies. The five studies are concerned with group cognition as developing within the process, in terms of emerging patterns in the conversations and actions. Group cognition is as such always process-like and situated within group work. They imply that it is not possible to "measure" it as a given state, or as an end state. Although group cognition in socio-cultural perspectives is not measurable separate from a certain process of activity, studies do differ in referring to group cognition concepts in three sequential moments (Matusov, 1996). According to Matusov (1996), group cognition can be perceived as a common ground (a shared background) between the group members that is activated in the group collaboration, as common engagement (shared activity), or as updated common ground (a shared experience) that is built during the collaboration. Considering these, the five studies also differed in their perceptions of the role of group cognition. Auer-Rizzi and Berry (2000) group participants that shared a business or a cultural background and looked how these backgrounds offered a common ground or frame of reference for those participants to collaborate more easily. Three studies (De Haan, 2001; Fiol, 1994; Granados, 2000) focused on the creation of group cognition as a common engagement among the participants who are directly involved in the joint activity, or, as Stone (1993, as cited in De Haan, 2001) wrote: "a continuous evolving mutual perspective on how to conceive the situation at hand." Hall et al. (2002) make it even more complicated 
by referring to group cognition in all three sequential moments, that is, to group cognition as common ground, as common engagement, and as updated common ground. They argue that group participants from different disciplines understand and use objects in strikingly different ways (sharing a disciplinary background provides common ground). The differences between participants can either go unnoticed or be put into coordinated use (common engagement) without explicit, group cognition. By studying a multi-disciplinary group working on a design problem, Hall et al. found that differences become remarkable either when a design proposal runs counter to deeply held disciplinary objectives or threatens to destabilize a wider network of tools and concepts (or representational infrastructure) used in that particular discipline. In such cases differences may disrupt or change the representational infrastructures that a disciplinary group relies on (updated common ground).

\subsubsection{Boundary crossing}

The three boundary crossing studies conceptualized cognition in terms of both stable mental model forms with information stored in memory and mental model states that are active and situated in the group collaboration. Accordingly, in the three boundary crossing studies the authors interpret the concept of shared in terms of "distributed": the knowledge necessary for the task is dispersed among the different members of the group (see Table 2). Derry et al. (1998) noted that a group distributed working memory would represent those thoughts from distributed long-term memory that becomes active within any individual's attention during the group discussion. Connecting this to the notion of group cognition, they write: "Obviously, only ideas that are shared (discussed) by one individual (and attended to by others) have the potential to modify a group's collective long-term memory" (p. 30). Similar to this, Banks and Millward (2000) define the central group cognition concept, shared mental model, as "a distributed system which runs a model collectively through the propagation of representational states across representational media". By that definition they point on the one hand to the stable form of mental models. As an example they refer to a mental model of a bath that will have a certain size and therefore maximum volume. These aspects refer to model form, and will not change. On the other hand they point to the dynamic configuration of the aspects of the model that can be changed when running the model. In the example this can be seen as the plug being in or not or as the amount of water actually in the bath at any point in time. These aspects refer to states, and are dynamic and depending on the specific situation.

The third boundary crossing study (Yoo \& Kanawattanachai, 2001) uses the concepts of transactive memory and collective mind to combine cognitive and socio-cultural perspectives on group cognition. With transactive memory, following Wegner, Erber, and Raymond (1991), they imply a "shared system for encoding, storing, and retrieving information". With collective mind they, following Weick and Roberts (1993), refer to a social cognitive system in which individuals heedfully interrelate their actions. Whereas transactive memory reflects the cognitive perspectives on group cognition, the concept collective mind reflects the socio-cultural perspectives on group cognition. The former refers to cognition within the minds of the group members, the latter points to cognition within group interaction. They draw upon these two concepts to examine how teams coordinate and interrelate their knowledge and actions in order to perform their tasks. In short, all three studies integrated elements of the cognitive perspectives (concepts like information processing, long-term memory, mental model form, transactive memory) and elements of the socio-cultural perspective (concepts such as situated cognition, distributed working memory, mental model state, collective mind) into an integrated approach centralized around the term distributed cognition. We summarize the integrated elements in these three studies in Table 3 below.

To measure group cognition, two of the studies used global measurement (see Table 2). They looked at the characteristics of the group as an entity (Banks \& Millward, 2000; Derry et al., 1998), through analysis of the group discourse and activity. The third study (Yoo \& Kanawattanachai, 2001) used questionnaires to ask each group member about

Table 3

Elements of the socio-genetic perspectives that are integrated in the boundary crossing studies

\begin{tabular}{|c|c|c|c|}
\hline Boundary crossing literature & $\begin{array}{l}\text { Elements of cognitive } \\
\text { perspectives }\end{array}$ & $\begin{array}{l}\text { Elements of socio-cultural } \\
\text { perspectives }\end{array}$ & Combined in a notion of \\
\hline Derry et al. (1998) & $\begin{array}{l}\text { Information-processing } \\
\text { (collective) long-term memory }\end{array}$ & $\begin{array}{l}\text { Situated cognition distributed } \\
\text { working memory }\end{array}$ & Distributed cognition \\
\hline Banks and Millward (2000) & $\begin{array}{l}\text { Shared mental models mental } \\
\text { model form }\end{array}$ & $\begin{array}{l}\text { Situated cognition mental } \\
\text { model state }\end{array}$ & Distributed cognition \\
\hline Yoo and Kanawattanachai (2001) & Transactive memory & Collective mind & Socially shared distributed cognition \\
\hline
\end{tabular}


the extent of group cognition in the group, with statements such as "Our team members had a global perspective that includes each other's decisions and the relationships among them." Since these perception measures formed the only basis for their analysis of the group cognition of the group, they recommended in their discussion that in future studies the contents of the communication interactions should also be examined.

With respect to the role of group cognition in relation to group processes and outcomes, the input-process-output model best represents the way the three studies dealt with group cognition (see Table 2). All three studies theoretically introduced group cognition partly as input for groups to work and partly as a process variable, developing during group working. Yoo and Kanawattanachai (2001) hypothesized that group cognition in terms of transactive memory of the group (input variable) had an influence on the group cognition in terms of the interrelation of actions during the group work (process variable). This latter was hypothesized as mediating the team performance. Derry et al. (1998) also noted group cognition of the group as input variable for the group to work in terms of overlap of prior knowledge, but their analysis focused only on the group cognition as a process variable (ideas shared during the interaction) which may influence the nature of the final group products. Banks and Millward (2000) studied group cognition as input in terms of the influence of shared and diverse information known to the team members, and group cognition as process variable in terms of the information that was shared during the group interaction.

\section{Comparing different conceptualizations of group cognition}

The purpose of this review is to explicate the various ways in which group cognition is conceptualized in the empirical literature in educational and psychological sciences. In doing so, this review wants to offer researchers a ground for conceptual clarity. It has been unclear how the empirical studies relate to each other as they use many different concepts as well as different, but often implicit, understandings of group cognition. We have reviewed the different conceptualizations and framed them in terms of socio-genetic views. This showed how respectively cognitive and socio-cultural perspectives on group cognition are discernable in the studies (see Table 4). The diversity in concepts, conceptualizations and methods turned out to be scattered around the research strands. By looking for a 'deeper' ground, that is by searching for theoretical perspectives, we have indicated a fundamental difference in point of view on group cognition, irrespective of the research strand or goal of the particular research. The following paragraphs discuss the differences, which appears to be similarities and complementarity of these different perspectives. Founded on this, it is questioned how future research can relate to these perspectives.

As described, the studies in the cognitive perspectives conceptualized and accordingly measured group cognition as a state of similarity or overlap between individual mental models. Thereby they localize cognition within the individual brain, and perceive it as a structure of elements (often in terms of knowledge). The focus of this perspective is on the state of (at least partly) unification of individuals' subjectivities. The studies in the socio-cultural perspective conceptualized and accordingly measured group cognition as a process of coordination of actions, or as a dynamic unity of individual contributions in the joint activity (Matusov, 1996; Weick \& Roberts, 1993). Cognition is then localized within the interrelated actions. It is also this activity which becomes the focus of the analysis. Considering these findings, it shows that these perspectives offer divergent conceptualizations of group cognition.

Along with these different conceptualizations, the studies connected to both perspectives use different key terms and even different discourses. The studies in the cognitive perspectives use academic terms such as information, knowledge, mental models, knowledge structures, building models, while the studies in the socio-cultural perspectives use academic terms such as participation, activity, interaction, processes and coordination. Furthermore, in the cognitive perspectives input-process-output models are used in studying processes, whereas in the studies with socio-cultural perspectives group cognition is considered to be a process-like and situated phenomenon, which continuously needs to be re-established.

Table 4

Cognitive versus socio-cultural perspectives on group cognition

\begin{tabular}{ll}
\hline Cognitive perspectives on group cognition & Socio-cultural perspectives on group cognition \\
\hline Viewed as a state (having in common) & Viewed as a process (continuously negotiated) \\
Focus on individual subjectivities & Focus on joint activity \\
Focus on unification of participants' subjectivities & Focus on coordination of contributions \\
Focus on consensus & Focus on diversity and dynamic unity \\
\hline
\end{tabular}


If we want to be able to make use of and build on these various studies and their differences, it becomes interesting and relevant to wonder how they could contribute to co-create a useful and coherent theory on group cognition. To reflect on this, we need to pose the question to what extent and in what ways are the differences in the conceptualizations between the theoretical perspectives complementary? Moreover, we need to question whether there are possibilities for synthesis between the perspectives. By conceptualizing group cognition as they do, what is it precisely that each of the perspectives leaves behind? As Greeno (1998) described, cognitive perspectives assume the decomposability of complex systems into a set of subsystems. Because of this assumption, the cognitive strategy is able to learn about the properties of each of these subsystems (an individuals' subjectivity) separately from the other subsystems, in order to build an understanding of the whole complex system. In relation to group cognition this means that one focuses on individuals' subjectivity (in terms of ones knowledge, mental model, or ones perspective), and then looks at the similarity between the individual's subjectivities. Socio-cultural perspectives assume systems of activity as "intact multiperson, human-technology systems" (Greeno, 1998). Hence, the socio-cultural tradition is able to learn about the intrinsic personality that complex systems (like groups or teams) endow, independent from those of its subsystems (individual members).

The drawback of each of these perspectives on group cognition seems to be exactly what is essentially highlighted by the other perspective. The cognitive tradition looses sight of the intrinsic nature of the complex system as a whole, and can only learn about it through the aggregation of the properties of subsystems. The shortcoming of this is that, in the end, groups are understood as some sort of sum of its members. In contrast, the socio-cultural tradition looses sight of the intrinsic nature of the subsystems, and learns about them only through the perspective of the system of which they are part. The drawback here is that subsystems (e.g., individuals, actions) are understood to be a function of their relations with other subsystems. Individuals are always participants of multiple social contexts. Anderson, Reder, and Simon (1997) noted that in such understandings, individuals tend to get 'absorbed' in the collectives of which they are part.

The above suggests the complementary makeup of both perspectives. In this review, we identified three studies that we perceived as boundary crossing. Let us return to these, and see what precisely these studies integrate and what we can learn from them regarding the complementary make-up of the perspectives. As we concluded, these three studies distinguish within their conceptualization of group cognition between a stable cognitive map or memory structure representing information and form, and dynamic, situated cognition representing coordination of information and actions. They focused on the interaction between these using the term distributed cognition in referring to this process of interaction. What they were able to do was to decompose subsystems within the whole complex system of a team and reveal their inherent properties, while simultaneously revealing the intrinsic nature of the complex system itself, separately from the subsystems. On the one hand, they identified individual subjectivities in terms of stable cognitive maps, and on the other hand they identified group processes in terms of the individual mental states situated in the interaction. So in a very precise and clear way they integrated in their focus the intrinsic nature of decomposable subsystems and the intrinsic nature of the whole system.

What follows is the question whether these studies, with integrating elements of both the cognitive and sociocultural perspectives, pursued a fair account of each of these two perspectives. Looking at their integration from the perspective of the cognitive perspectives, one would say that they indeed managed to create a complete picture of cognition, extending individual cognition as structures within the individual mind to include situated processes in which cognition becomes mental states or the processing of information.

Considering the practice of integration in these studies from the perspective of socio-cultural thinking, one doubts if it accounts for the socio-cultural tradition in the end. Of course, by focusing on distributed cognition, the studies considered not only the individual cognition but also the cognition that is situated in the activity processes. But, what is questionable in terms of socio-cultural thinking is treating cognition itself as decomposable. Distributed cognition is, at least in the three studies discussed here, treated as dividing up the cognitive processes taking place within the heads of individuals (individual cognition in terms of mental models, memory) and the processes taking place in the interaction (situated cognition). The situated cognition in fact only refers to the information that is conversationally shared between these individuals. And with the term distributed cognition the studies signify that not all information relevant for a specific situation needs to be conversationally shared between all individuals, in order to build up the informational structure that is needed to coordinate the collaborative work well. Although choosing the term distributed cognition instead of situated cognition, the emphasis in these studies remains on exactly these informational structures, whereby information is divided amongst the individuals. To understand the collaboration processes it becomes most relevant to 
pinpoint the properties (e.g., contents of information) of the structures at specific times. Socio-cultural perspectives instead, perceive cognition (whether using the term situated or distributed) as the socially developed routine practices themselves, and rather focus on the dynamic transformation within these practices. Individual cognition is defined by its relations to social practices, as is illustrated by the following quote of Greeno (1998):

Regularities of an individual's activities, in a trajectory that spans participation at different times in a community and participation in different communities, are characterized as the individual's identity (Wenger, 1998), which is coconstituted by the individual's relation of those communities to the individual (Mead, 1934, p. 6).

In terms of socio-cultural perspectives, individual cognition is considered not as a property of structures (e.g., autonomous agents have knowledge), but rather as a continuous process of relation (e.g., participants knowing during practice). Despite the complementary nature of the two perspectives, it seems the boundary crossing literature about group cognition followed the cognitive perception of cognition and did not manage to fully account for the basic assumptions of socio-cultural perspectives.

\section{Towards one theoretical perspective on group cognition?}

What are the directions that future research can take? Is it advisable to strive for a coherent theory on group cognition, or is it better to have the two perspectives, as the differences are insurmountable? These matters raise the more fundamental question if it is at all possible for the two perspectives to reconcile or synthesize? Scrutinizing some of the most recent discussions and efforts of transcending the cognitive and socio-cultural perspectives (Anderson, Reder, \& Simon, 1996, 1997; Billet, 1996; Cobb \& Bowers, 1999; Gauvain, 2004; Glick, 2004; Greeno, 1997, 1998; Packer \& Goicoechea, 2000; Saxe \& Simonde, 2004), we conclude that there are three possible answers on this question.

First, one could say that it is not possible for the cognitive and the socio-cultural perspectives to be brought together, since both are different "theories", and theories are in essence incommensurable, because a theory has its own conceptual object and means of researching it (Glick, 2004), and its own questions and framing of assumptions (Greeno, 1997). Packer and Goicoechea (2000) even go so far as to state that the cognitive perspectives and socio-cultural perspectives not only differ in their epistemological assumptions (when is knowledge valid, what counts as truth), but also in their ontological assumptions (what is, what exists, and what it means for something to be). They stated that cognitive perspectives imply a dualist ontological approach, in which construction is viewed only as a cognitive activity in which subjectivity structures and shapes data that comes from a distinct and separate objective world. As opposed to that, socio-cultural perspectives bring forward a non-dualistic ontological approach, in which subjectivities and the objects themselves are constructed and mutually define each other. We found substantial differences in conceptualizations between the studies within the cognitive perspectives and the studies within the socio-cultural perspectives. And indeed, reconsidering the socio-genetic framework in which the studies could be placed, the two perspectives reflect assumptions that seem ontologically different. Cognitive perspectives seem to assume that things (e.g., individuals or mental models) can exist independently, although it can change by its relations. Socio-cultural perspectives seem to assume an ontology in which things only exist in relation to other things (individuals are participants; minds are situated in social action). Because of these differences, Glick emphasizes that the only level at which a relationship between these perspectives can be sought is at the level of contributing to an arsenal of explanatory devices, perceiving theories and perspectives as tools.

A second answer is that it is possible for the two perspectives to start a true dialogical engagement. In fact, such a dialogical engagement was started between Anderson, Reder, and Simon $(1996,1997)$ representing the cognitive perspectives and Greeno (1997) representing the socio-cultural perspectives. After this exchange, which had more the undertone of a debate, these authors arrived at conclusion to their discussion (Anderson, Greeno, Reder, \& Simon, 2000). Besides stating some very obvious educational matters on which the perspectives agreed, they noted that the different perspectives do propose alternative explanations for phenomena, but are each in an incomplete state, showing the need for further reconciliation. In reaction to this discussion, Cobb and Bowers (1999) wrote to be skeptic about the prospect of a dialogical engagement, saying: "In our view, a continuing intellectual exchange of the type envisioned by Greeno is virtually impossible unless proponents of each perspective come to understand the basic tenets of the other viewpoint" (p. 6). They emphasize that the discussion between Greeno (1998) and Anderson et al. (2000) proved that basic assumptions of the one perspective leads to misinterpreting the arguments of the other perspective. According to them, a dialogue can only be started through the development of a viable basis for communication. Alternative to an 
explicit scientific dialogue like the one between Greeno and Anderson et al. would be an attempt of each to resolve its own drawbacks by reckoning the highlights and explanations of the other perspective. This is also proposed by Greeno, who discusses two possible routes:

o To take the theory of individual cognition (here cognitive perspectives) as its basis and build toward a broader theory by incrementally developing analyses of additional components of situations that are considered as contexts for cognitive processes;

o To take the theory of social and ecological interactions (here socio-cultural perspectives) as its basis and build toward a more comprehensive theory by developing increasingly detailed analyses of structures of information that are produced by the interactions people have with each other and with the material and representational resources in their environments.

The analysis of the studies that we considered as boundary crossing literature showed that these studies are exactly a reflection of the first route, in which they depart from cognitive perspectives and attempt to extend it by including situated accounts of cognition. Before, we noted that Thompson (1998) described this route more generally in terms of a current movement of the cognitive perspectives. It seems that the socio-cultural tradition would construct the integration seen in the three boundary crossing studies in a different way. In our review, we have not found empirical studies reflecting the second route. Suggestions for the second route were made by Greeno (1998), Valsiner and Van der Veer (2000), and Packer and Goicoechea (2000). For the socio-cultural tradition, these suggestions imply defining individual cognition as structures of socio-cultural relations (which is a translation of the informational elements within the studies in the cognitive tradition). As Packer and Goicoechea illustrate, an integration of the second route, means that the ontological assumptions implied by the cognitive perspectives are included, but only secondary; the dualism of subject and object becomes a reality through the non-dualistic processes of their coming into being. Valsiner and Van der Veer (2000) and Hermans and Kempen (1993) implement this second route by considering the individual as a dialogical system by itself. Cognition is then defined as an individual property, but the individual itself is an inherently social entity, constituted through its social relations with others.

A third answer to the question about the reconciliation between the perspectives is that it would be possible to synthesize them into one coherent theory. Although the boundary crossing literature can be considered as attempts of synthesizing the perspectives, we also concluded that they did not succeed in a complete synthesis because of their neglect of some basic assumptions of the socio-cultural perspectives. We see a similar problem with theoretical attempts to transcend differences between the cognitive and the socio-cultural perspectives. For example, recently, Saxe and Simonde (2004) and Gauvain (2004) claimed to work towards an integrated view of human development. Central to their integration is the assumption that cognition should be understood in a framework embedding cognition in a social-historical context. The basic assumptions from which they depart indicate that, instead of a full synthesis, their integration reflects more the second route that Greeno (1998) described. They depart from a socio-cultural perspective and include precise accounts of individual cognition.

Reflecting on these three answers, it seems that a complete integration of the two perspectives is not possible; each perspective in its current status has in a sense its own object and a full integration at this point would mean loosing sight of some of the basic assumptions of one of the perspectives. Following Greeno's suggestion, we think that the most meaningful first step to bring together the values of both the cognitive perspectives and the socio-cultural perspectives is for each perspective to extend itself to include some of the explanations offered by the other perspective.

This first step of cross-fertilization, however, requires researchers first to question carefully their basic assumptions (e.g., using Table 4) in conceptualizing group cognition, and relate themselves to more fundamental theoretical perspectives (e.g., using Table 1). Only then, it is possible to fully grasp the specific conceptualization of group cognition that is used and to build forward on the findings of these studies. Besides, we suggest researchers to choose terminology and methodologies accordingly (e.g., using analysis columns in Table 2). For as each researcher clarifies their premises, future attempts for cross-fertilization are facilitated. This review supplies the tools for this effort by offering a dialectic re-conceptualization of the existing diverse terminology, and the identification of the conflicting premises and methodologies. By this, it lays the ground for conceptual clarity that enables to build on each other's work. Concerning future research aiming at incorporating aspects of both perspectives on group cognition, the approach of the studies identified in this review as boundary crossing can be regarded as valuable and promising, since they try to include aspects from a different perspective on group cognition. We regard the two possible routes of integrations crucial for 
future studies to work towards more coherent theories of the concept of group cognition. By either extending cognitive conceptualizations of group cognition to include social accounts of cognition or by extending socio-cultural conceptualizations of group cognition to include more precise accounts of individual cognition, we believe the studies on group cognition would be more complete. They would both, in their own ways provide answer to the critical socio-genetic question posed by Valsiner and Van der Veer (2000): "How to construe persons as being social without abandoning their obvious personal autonomy, separateness from any social unit (group, crowd, community), while being members of such units?" (p. 6).

Groups of people are increasingly acknowledged as the source of knowledge construction (Akkerman, Admiraal, Simons, \& Niessen, 2006). Team learning has become a cornerstone of organizational life and it is increasingly being capitalized on in educational settings (Van den Bossche, Gijselaers, Segers \& Kirschner, 2006). In this context, the construct of group cognition is proposed as a central issue in research on team learning (Roschelle, 1992; Webb \& Palincsar, 1996). The development of group cognition is a process of negotiating and interrelating diverse views of group members. This process enables group members to learn from others' preferences and viewpoints by facing different viewpoints and by accepting the existence of them as legitimate (Engeström et al., 1995). This implies that in order to better understand how team learning works and under which conditions it is effective, research on the processes in and through which group cognition is actually developing is promising.

A clear conceptualization of group cognition is a necessary condition for designing empirical studies on group learning. Moreover, in order to deepen our understanding of the process of team learning in educational and organisational settings, building on previous research is a conditio sine qua non. This asks for conceptual clarity of the core concepts and the methodology used. The conceptual framework offered in this review can be used as a tool for educational researchers to define the conceptual framework of their study and to argue on the methodological choices made.

\section{Acknowledgements}

The second author was supported by a grant from the Dutch institute of Scientific Research (NWO), grant number 014-43-704.

\section{Appendix A}

Description of each study

\begin{tabular}{|c|c|c|c|c|}
\hline $\mathrm{Nr}$ & Studies & $\begin{array}{l}\text { Group cognition concepts } \\
\text { used in article [cursive is the } \\
\text { term by which the article is } \\
\text { found] }\end{array}$ & Definition: group cognition & Analysis of group cognition \\
\hline \multirow[t]{2}{*}{1} & $\begin{array}{l}\text { Yoo and Kanawattanachai } \\
\text { (2001). Developments of } \\
\text { transactive memory systems } \\
\text { and collective mind in virtual } \\
\text { teams }\end{array}$ & $\begin{array}{l}\text { Socially shared distributed } \\
\text { cognition, collective mind, } \\
\text { transactive memory }\end{array}$ & Interrelation between: & $\begin{array}{l}\text { 1. Aggregation of intra group } \\
\text { responses on four 5-point } \\
\text { Likert scales questions about } \\
\text { acting, understanding and } \\
\text { interrelating in the team }\end{array}$ \\
\hline & & & $\begin{array}{l}\text { 1. collective mind = social } \\
\text { cognitive system in which } \\
\text { individuals heedfully interrelate } \\
\text { their actions (Weick \& Roberts, } \\
\text { 1993) } \\
\text { 2. transactive memory = shared } \\
\text { system for encoding, storing, and } \\
\text { retrieving information (Wegner et } \\
\text { al., 1991) }\end{array}$ & $\begin{array}{l}\text { 2. Aggregation of intra group } \\
\text { responses on three 5-point } \\
\text { Likert scales questions about } \\
\text { who knows what }\end{array}$ \\
\hline 2 & $\begin{array}{l}\text { Derry et al. (1998). Individual } \\
\text { and distributed cognitions in } \\
\text { interdisciplinary teamwork: a } \\
\text { developing case study and } \\
\text { emerging theory }\end{array}$ & $\begin{array}{l}\text { Distributed cognitions, } \\
\text { compatible mental models, } \\
\text { shared cognitions, common } \\
\text { voice, shared perspectives, } \\
\text { shared knowledge, collective } \\
\text { intelligence }\end{array}$ & $\begin{array}{l}\text { Compatible understandings of the } \\
\text { task and team that become } \\
\text { sufficiently aligned }\end{array}$ & $\begin{array}{l}\text { The degree to which resulting } \\
\text { ideas represent cognitions } \\
\text { that have been more or less } \\
\text { processed by group } \\
\text { discussions }\end{array}$ \\
\hline
\end{tabular}


Appendix A (Continued)

\begin{tabular}{lll}
\hline $\mathrm{Nr}$ Studies & Group cognition concepts & Definition: group cognition \\
& used in article [cursive is the & \\
& term by which the article is \\
& found] & \\
&
\end{tabular}

$3 \quad$ Mohammed and Ringseis (2001). Cognitive diversity and consensus in group decision making: The role of inputs, processes, and outcomes

4 Levesque et al. (2001). Cognitive divergence and shared mental models in software development project teams influence of shared mental models on team process and performance

Banks and Millward (2000).

Shared mental models

Cognitive consensus, shared assumptions, group representation, collective representation, shared cognition

Shared mental models, shared cognition, common understanding, shared understanding, group mental models, shared view

Representational infrastructure, shared understandings, distributed cognition

Shared mental models, common mental models, shared vision, common vision models as a distributed cognitive process
Similarity among group members regarding how key matters are conceptualized

'Knowledge structures held by members of a team that enable them to form accurate explanations and expectations for the task, and in turn to coordinate their actions and adapt their behaviour to demands of the task and other team members' (Cannon-Bowers et al., 1993) 1. Sometimes explicit same understandings about proposed activity and its meaning

\section{Across disciplines:} infrastructures that enables coordinated action between communities with different interests, needs, and accountabilities

Convergence of individual mental models; mental model $=$ 'mechanism whereby humans generate descriptions of system purpose and form, explanations of system functioning and observed system states, and predictions of future system states' (Rouse \& Morris, 1986);

A distributed system which runs a model collectively trough the propagation of representational states across representational media; mental model form $=$ the homographic mapping consisting of elements and their relations which represent the thing being modeled; the mental model state $=$ the dynamic configuration of the aspects of the model that can be changed when running the mode
The degree of variation of group participants' responses on five-item 7-point Likert scale questions about how they interpreted the task (=negative measure)

Overall intra-team similarity on team process items ( 22 items covering communication processes, climate, structure, progress) and team expertise ratings (ratings of each other's expertise)

The degree to which coordinated action is reached, despite different ways in which people position themselves and others with respect to relevant events

Correlation between matrices of individual ratings of the relations between critical (team and task based) attributes

Comparison of the differences in the types of communications (model form interaction, model states interaction, and honing, widening or supporting states) between the distribution conditions (receiving either information completely, or on complete modules, or only part of the modules) 
Appendix A (Continued)

$\mathrm{Nr} \quad$ Studies
Group cognition concepts used in article [cursive is the term by which the article is found] Peterson et al. (2000). Collective efficacy and aspects of shared mental models as predictors of performance over time in work groups

Ensley and Pearce (2001). Shared cognition in top management teams: Implications for new venture performance

10 Rutkowski and Smits (2001). Constructionist theory to explain effects of GDSS

11 Fiol (1994). Consensus, diversity, and learning in organizations

\section{Shared mental models, shared} cognition, transactive memory, group schemata, intersubjectivity, collective mind, group situation awareness, team schema similarity

Shared cognition, shared strategic cognition mental models, group vision

Collective agreement, consensus, common understanding, common view, collective understanding, common mind
Shared meaning; shared

Definition: group cognition

Analysis of group cognition

Cognitive representations of task requirements, procedures and role responsibilities that members hold in common

The extent to which the mental models about strategy are shared

1. Constructionist conceptualize meaning as the expression of a specific pattern of coordinated interactions, internalized in concepts and reproducible quasi-individually each time an object is recognized and referred to the internalized process 2. Constructivist conceptualize meaning as brain-based (cognitive schemes) [no specific definition is given when something is shared] Convergence around (a specific dimension of) meaning
Average of pair-wise comparisons between the amount of points attributed in the individual questionnaires; points attributed to:

1. the extent of contributions of the group members to the task (indicating 'disagreement of contributions') 2. the extent of contributions of oneself to the task (indicating egotism) 3. the importance of task components for producing good results

Coefficient of variation of individual answers on 33 seven dimension scale items about business level strategy

?

The extent of progressive convergence across subgroups in patterns of:

1. certainty of positions

2. perceived judgement of issues

3. perceived controllability of issues

4. scope of the arguments; as seen in the content and framing of expressions in the logged group entries 
Appendix A (Continued)

\begin{tabular}{llll}
\hline $\mathrm{Nr}$ & Studies & $\begin{array}{l}\text { Group cognition concepts } \\
\text { used in article [cursive is the } \\
\text { term by which the article is } \\
\text { found] }\end{array}$ & Definition: group cognition \\
\hline 12 & $\begin{array}{l}\text { Hare and O'Neill (2000). } \\
\begin{array}{l}\text { Effectiveness and efficiency } \\
\text { in small academic peer }\end{array}\end{array}$ & $\begin{array}{l}\text { Shared vision, shared } \\
\text { understanding }\end{array}$ & $\begin{array}{l}\text { Sense of commonality which } \\
\text { gives coherence to diverse } \\
\text { activities }\end{array}$
\end{tabular}

groups

13 Langan-Fox et al. (2001). Analyzing shared and team mental models

14 Carley (1997). Extracting team mental models through textual analysis
Shared mental model/team mental models (as distinct concepts)

Team mental models .

$15 \quad$ Mulder et al. (2002).

Assessing group learning and shared understanding in technology-mediated interaction

16

Granados (2000).

Constructing intersubjectivity in representational design activities
Shared understanding, common understanding

Intersubjectivity; common ground, mutual understanding, common understanding
The extent to which a group (dyad) of individuals possesses a similar cognitive representation for some situation or phenomenon

'Shared' or 'social' knowledge; (lossy) intersection of the individual mental maps

Mutual knowledge, mutual beliefs, and mutual assumptions (Clark \& Brennan, 1991)

Establishing and maintaining a common understanding in communication, through common ground (mutual knowledge, mutual beliefs and mutual assumptions) and grounding (a coordination of process)

Finding common ground for different business and cultural assumptions during decision making
Analysis of group cognition

The result of a content analysis (affinity clustering technique) of the responses in individual interviews on 25 questions eliciting in-depth responses in a.o. the area of shared vision, mission and goals

The average (negatively calculated) of the dyadic differences between group participants' ratings of similarity between concepts

A team cognitive map, representing the (lossy) intersection of individual cognitive maps; an individual cognitive map consists of both concepts and the relationships between them, as extracted from individual answers on open-ended questions

Means of the individual ratings on four 6/7 Likert scale items about the individual and group understanding of content, the procedure, the tools, and each other

Patterns of marking in communication by the participants to define, constrain, and maintain their understanding of the task at hand (e.g. including knowledge, setting goals, setting actions), as coded in the transcription of video segments

Commonality of business and national assumptions about social relationships and preference for communication styles, as induced from argumentation during decision-making and in-depth interviews assumptions; shared culture, common ground making: interactions among

Austrian, Finnish and

Swedish Business Students 
Appendix A (Continued)

$\mathrm{Nr} \quad$ Studies

19

Marks et al. (2002). The impact of cross-training on team effectiveness

20 Stout et al. (1999). Planning, shared mental models, and coordinated performance: An empirical link is established

Edelson (2000). The influence of supervisor-subordinate mental model congruence on group effectiveness and subordinates' satisfaction with their supervisor

\author{
Group cognition concepts \\ used in article [cursive is the \\ term by which the article is \\ found]
}

Definition: group cognition

Analysis of group cognition
Overlap between private models of group participants representing an understanding of the object of activity
Shared team-interaction mental models, shared mental models

Shared mental model; shared expectations; shared understanding; common understanding

Shared mental models
Similarity among team members' team-interaction mental models; mental models is the content and organization of inter-role knowledge held by team members within a performance setting; team interaction models contains procedural knowledge about members' roles and task at particular times

Common understanding of who is responsible for what task and what the information requirements are
Similarity between mental models of people; mental models $=$ working models in the brains of people to understand the world and predict its happenings, by simplifying reality to permit adequate and rapid prediction of a system's behavior
Overlap between the internal private model representing the user's understanding of the object of the development activity and the internal private model representing the developer's understandings as inferred by the verbal and nonverbal communications which is presented through the interaction

1. (Experiment 1:) average similarity between team members' individual ratings of the relations among critical task concepts

2. (Experiment 2:) the percentage of concepts placed identically on the concept maps

Degree of similarity (index C using pathfinder) between team members' configural networks; one member's configural network is based on 190 judgments of the relatedness of concepts on 7 point Likert-scale

(Calculated negatively:)

1. The mean difference of answers between the group members on 59 questions about the supervisor's interaction with the group 2. The mean difference of answers between the group members and between the supervisor on 365 -point Likert scale questions about the supervisor's interaction with the group 
Appendix A (Continued)

\begin{tabular}{|c|c|c|c|c|}
\hline $\mathrm{Nr}$ & Studies & $\begin{array}{l}\text { Group cognition concepts } \\
\text { used in article [cursive is the } \\
\text { term by which the article is } \\
\text { found] }\end{array}$ & Definition: group cognition & Analysis of group cognition \\
\hline 22 & $\begin{array}{l}\text { De Haan (2001). } \\
\text { Intersubjectivity in models of } \\
\text { learning and teaching: } \\
\text { reflections from a study of } \\
\text { teaching and learning in a } \\
\text { Mexican Mazahua } \\
\text { community }\end{array}$ & $\begin{array}{l}\text { Distributed cognition, } \\
\text { intersubjectivity, joint } \\
\text { meaning, common } \\
\text { understanding, mutual } \\
\text { understanding, common } \\
\text { perspective, communality, } \\
\text { transference of perspectives, } \\
\text { perspective building, } \\
\text { coordination of actions }\end{array}$ & $\begin{array}{l}\text { 1. Context creation: the kind of } \\
\text { efforts put into establishing } \\
\text { intersubjectivity; } 2 \text {. Identity of } \\
\text { interlocutors: the kind of roles or } \\
\text { identities that are assumed or } \\
\text { created; } 3 \text {. The kind of } \\
\text { communicative structures and } \\
\text { means created to organize } \\
\text { common understanding }\end{array}$ & $\begin{array}{l}\text { Sequences of participation } \\
\text { and control strategies } \\
\text { showing: } \\
\text { 1. if context creation was } \\
\text { based either on assuming } \\
\text { communality versus the need } \\
\text { to overcome the differences } \\
\text { between individual worlds } \\
\text { through explicit } \\
\text { communicative efforts, } \\
\text { 2. identify of interlocutors } \\
\text { with both having } \\
\text { responsibility for establishing } \\
\text { intersubjectivity, } \\
\text { 3. communicative structures } \\
\text { and means to organize } \\
\text { common understanding either } \\
\text { parallel or sequentially, and } \\
\text { either continuously or } \\
\text { through segmentation of the } \\
\text { activity }\end{array}$ \\
\hline
\end{tabular}

\section{References $^{4}$}

Akkerman, S., Admiraal, W., Simons, R. J., \& Niessen, T. (2006). Considering diversity: Multivoicedness in international academic collaboration. Culture \& Psychology, 12, 461-485.

Anderson, J. R., Greeno, J. G., Reder, L. M., \& Simon, H. A. (2000). Perspectives on learning, thinking, and activity. Educational Researcher, 29, $11-13$.

Anderson, J. R., Reder, L. M., \& Simon, H. A. (1996). Situated learning and education. Educational Researcher, $25,5-11$.

Anderson, J. R., Reder, L. M., \& Simon, H. A. (1997). Situative versus cognitive perspectives: Form versus substance. Educational Researcher, 26, $18-21$.

*Auer-Rizzi, W., \& Berry, M. (2000). Business vs. cultural frames of reference in group decision making: Interactions among Austrian, Finnish, and Swedish business students. The Journal of Business Communication, 37, 264-292.

Axelrod, R. (1976). The structure of decision. Princeton, NJ: Princeton University Press.

Bakhtin, M. M. (1981). The dialogic imagination: Four essays. Austin, TX: University of Texas Press.

Bakhtin, M. M. (1986). Speech genres and other late essays. Austin, TX: University of Texas Press.

*Banks, A. P., \& Millward, L. J. (2000). Running shared mental models as a distributed cognitive process. British Journal of Psychology, 91 , $513-531$.

Barron, B. (2000). Achieving coordination in collaborative problem-solving groups. The Journal of the Learning Sciences, 9, $403-436$.

Billet, S. (1996). Situated learning: Bridging sociocultural and cognitive theorising. Learning and Instruction, 6, 263-280.

Cannon-Bowers, J. A., \& Salas, E. (2001a). Special issue preface. Journal of Organizational Behavior, 22, 87-88.

Cannon-Bowers, J. A., \& Salas, E. (2001b). Reflections on shared cognition. Journal of Organizational Behavior, 22, $195-202$.

Cannon-Bowers, J. A., Salas, E., \& Converse, S. (1993). Shared mental models in expert team decision making. In N. John Castellan Jr. (Ed.), Individual and group decision making: Current issues (pp. 221-246). Hillsdale, NJ: Lawrence Erlbaum.

*Carley, K. M. (1997). Extracting team mental models through textual analysis. Journal of Organizational Behavior, 18, $533-558$.

Clark, H. H., \& Brennan, S. E. (1991). Grounding in communication. In L. B. Resnick, J. M. Levine, \& S. D. Teasley (Eds.), Perspectives on socially shared cognition (pp. 127-149). Washington, DC: American Psychological Association.

Cobb, P., \& Bowers, J. (1999). Cognitive and situated learning perspectives in theory and practice. Educational Researcher, 28, 4-15.

\footnotetext{
${ }^{4}$ Studies indicated with $*$ are included in the review.
} 
Cooke, N. J., Salas, E., Cannon-Bowers, J. A., \& Stout, R. (2000). Measuring team knowledge. Human Factors, 42, $151-173$.

Cohen, S. G., \& Bailey, D. E. (1997). What makes teams work: Group effectiveness research from the shop floor to the executive suite. Journal of Management, 23(3), 239-290.

Crook, C. (1998). Children as computer users: The case of collaborative learning. Computers and Education, 30, $237-247$.

*De Haan, M. (2001). Intersubjectivity in models of learning and teaching: Reflections from a study of teaching and learning in a Mexican Mazahua community. In S. Chaiklin (Ed.), The theory and practice of cultural-historical psychology (pp. 174-199). Aarhus, Denmark: Aarhus University Press.

*Derry, S. J., DuRussel, L. A., \& O’Donnell, A. M. (1998). Individual and distributed cognitions in interdisciplinary teamwork: A developing case study and emerging theory. Educational Psychology Review, 10, 25-56.

Dillenbourg, P., Traum, D., \& Schneider, D. (1996). Grounding in multi-modal task-oriented collaboration, In W. Wahlster (Ed.), Proceedings of the 12th European Conference on Artificial Intelligence. Chichester, UK: John Wiley \& Sons.

*Druskat, V. U., \& Pescosolido, A. T. (2002). The content of effective teamwork mental models in self-managing teams: Ownership, learning and heedful interrelating. Human Relations, 55, 283-314.

*Edelson, R. E. (2000). The influence of supervisor-subordinate mental model congruence on group effectiveness and subordinates' satisfaction with their supervisor. Unpublished doctoral dissertation, The Claremont Graduate University, Claremont.

Engeström, Y., Engeström, R., \& Kärkkäinen, M. (1995). Polycontextuality and boundary crossing in expert cognition: Learning and problem solving in complex work activities. Learning and Instruction, 5, 319-336.

*Ensley, M. D., \& Pearce, C. L. (2001). Shared cognition in top management teams: Implications for new venture performance. Journal of Organizational Behavior, 22(2), 145-160.

*Fiol, C. M. (1994). Consensus, diversity, and learning organizations. Organization Science, 5, 403-420.

Gauvain, M. (2004). The contribution of contextual and sociocultural approaches to developmental theory. Paper presented at the meeting of the American Educational Research Association, San Diego, CA.

Glick, J. (2004). Coordinating cognitive and socio-cultural perspectives: How? Paper presented at the meeting of the American Educational Research Association, San Diego, CA.

Granados, R. (2000). Constructing intersubjectivity in representational design activities. Journal of Mathematical Behavior, 19, 503-530.

Greeno, J. G. (1997). On claims that answer the wrong questions. Educational Researcher, 26, 5-17.

Greeno, J. G. (1998). The situativity of knowing, learning and research. American Psychologist, 53, 5-26.

*Hall, R., Stevens, R., \& Torralba, T. (2002). Disrupting representational infrastructure in conversations across disciplines. Mind, Culture and Activity, 9, 179-210.

Hare, L. R., \& O’Neill, K. (2000). Effectiveness and efficiency in small academic peer groups. Small Group Research, 31 , 24-53.

Hermans, H. J. M., \& Kempen, H. J. G. (1993). The dialogical self: Meaning as movement. San Diego, CA: Academic Press.

Homan, T. (2001). Teamleren. Theorie en facilitatie. [Teamlearning. Theory and facilitation]. Schoonhoven, the Netherlands: Academic Services.

Hutchins, E. (1995). Cognition the Wild. Cambridge, MA: MIT Press.

Johnson-Laird, P. N. (1983). Mental models: Towards a cognitive science of language, inference and consciousness. Cambridge, MA: Harvard University Press.

Kaufer, D. S., \& Carley, K. M. (1993). Communication at a distance: The effect of print on socio-cultural organization and change. Hilsdale, NJ: Lawrence Erlbaum.

Klimoski, R., \& Mohammed, S. (1994). Team mental model: Construct or metaphor? Journal of Management, 20, $403-437$.

Kraiger, K., Salas, E., \& Cannon-Bowers, J. A. (1993). Measuring knowledge organization as a method for assessing learning during training. Human Factors, 37, 804-816.

Langan-Fox, J., Code, S., \& Langfield-Smith, K. (2000). Team mental models: techniques, methods, and analytic approaches. Human Factors, 42, $242-271$

*Langan-Fox, J., Wirth, A., Code, S., Langfield-Smith, K., \& Wirth, A. (2001). Analyzing shared and team mental models. International Journal of Industrial Ergonomics, 28, 99-112.

Leontev, A. N. (1978). Activity, consciousness and personality. Englewood Cliff's, NJ: Prentice-Hall.

*Levesque, L. L., Wilson, J. M., \& Wholey, D. R. (2001). Cognitive divergence and shared mental models in software development teams. Journal of Organizational Behavior, 22, 135-144.

Luria, A. R. (1976). Cognitive Development: Its Cultural and Social Foundations. Cambridge, MA: Harvard University Press.

* Marks, M. A., Burke, C. S., Sabella, M. J., \& Zaccaro, S. J. (2002). The impact of cross-training on team effectiveness. Journal of Applied Psychology, 87, 3-13.

*Mathieu, J. E., Heffner, T. S., Goodwin, G. F., Salas, E., \& Cannon-Bowers, J. A. (2000). The influence of shared mental models on team process and performance. Journal of Applied Psychology, 85, 273-283.

Matusov, E. (1996). Intersubjectivity without agreement. Mind, Culture and Activity, 3, 25-45.

Mead, G. H. (1934). Mind, self and society form the standpoint of a social behaviourist. Chicago: University of Chicago Press.

Mohammed, S., \& Dumville, A. B. C. (2001). Team mental models in a team knowledge framework: Expanding theory and measurement across disciplinary boundaries. Journal of Organizational Behavior, 22, 89-106.

Mohammed, S., Klimoski, R., \& Rentsch, J. (2000). The measurement of team mental models. We have no shared schema. Organizational Research Methods, 3, 123-165.

*Mohammed, S., \& Ringseis, E. (2001). Cognitive diversity and consensus in group decision making: The role of inputs, processes and outcomes. Organizational Behavior and Human Decision Processes, 85, 310-335.

*Mulder, I., Swaak, J., \& Kessels, J. (2002). Assessing group learning and shared understanding in technology-mediated interaction. Educational Technology and Society, 5, 35-47. 
*O'Neill, E., Johnson, P., \& Johnson, H. (1999). Representations in cooperative analysis and design for system development. Human Computer Interaction, 14, 43-91.

Packer, M. J., \& Goicoechea, J. (2000). Sociocultural and constructivist theories of learning: Ontology, not just epistemology. Educational Psychologist, 35, 227-241.

*Peterson, E., Mitchell, T., Thompson, L., \& Burr, R. (2000). Collective efficacy and aspects of shared mental models as predictors of performance over time in work groups. Group Processes \& Intergroup Relations, 3, 296-316.

Rentsch, J. R., \& Hall, R. J. (1994). Members of great teams think alike: A model of the effectiveness and schema similarity among team members. Advances in Interdisciplinary Studies of Work Teams, 1, 223-261.

Roschelle, J. (1992). Learning by collaborating: Convergent conceptual change. Journal of the Learning Sciences, 2, $235-276$.

Rouse, W. B., \& Morris, N. M. (1986). On looking into the black box: Prospects and limits in the search for mental models. Psychological Bulletin, 100, 349-363.

*Rutkowski, A. F., \& Smits, M. S. (2001). Constructionsist theory to explain effects of GDSS. Group Decision and Negotiation, 10, 67-82.

Salomon, G., \& Perkins, D. N. (1998). Individual and social aspects of learning. Review of Research in Education, 23, 1-24.

Saxe, G.B., Simonde, I. (2004). Unintented consequences: The shifting structure of the Oksapmin's Indigenous Number System. Paper presented at the meeting of the American Educational Research Association, San Diego, CA.

Schneider, S. C., \& Angelmar, R. (1993). Cognition in organizational analysis: Who's minding the store? Organization Studies, 14, $347-374$.

Sfard, A. (1998). On two metaphors for learning and the danger of choosing just one. Educational Researcher, 27, 4-13.

Stahl, G., Koschmann, T., \& Suthers, D. (2006). Computer-supported learning. In R. K. Sawyer (Ed.), Cambridge handbook of the learning sciences (pp. 409-426). Cambridge, UK: Cambridge University Press.

Stone, C. A. (1993). What is missing in the metaphor of scaffolding? In E. A. Forman, N. Minick, \& C. A. Stone (Eds.), Contexts for learning: Sociocultural dynamics in children's development (pp. 169-183). Oxford, UK: Oxford University Press.

*Stout, R. J., Cannon-Bowers, J. A., Salas, E., \& Milanovich, D. M. (1999). Planning, shared mental models, and coordinated performance: An empirical link is established. Human Factors, 41, 61-71.

Suthers, D. D. (2005). Technology affordances for intersubjective learning: A thematic agenda for CSCL. In T. Koschmann, D. Suthers, \& T. W. Chan (Eds.), Computer supported collaborative learning 2005: The next 10 years! (pp. 662-671). Mahwah, NJ: Lawrence Erlabaum Associates.

Thompson, L. (1998). A new look at social cognition in groups. Basic \& Applied Social Psychology, 20, 3-5.

Thompson, L., \& Fine, G. A. (1999). Socially shared cognition, affect, and behavior: A review and integration. Personality and Social Psychology Review, 3, 278-302.

Valsiner, J., \& Van der Veer, R. (2000). The social mind. Construction of the idea. Cambridge, UK: Cambridge University Press.

Van den Bossche, P., Gijselaers, W., Segers, M., \& Kirschner, P. A. (2006). Social and Cognitive Factors Driving Teamwork in Collaborative Learning Environments. Team Learning Beliefs \& Behaviors. Small Group Research, 37(5), 490-521.

Vygotsky, L. S. (1978). Mind in society. Cambridge, MA: Harvard University Press.

Webb, N. M., \& Palincsar, A. S. (1996). Group processes in the classroom. In D. C. Berliner \& R. C. Calfee (Eds.), Handbook of educational psychology (pp. 841-873). New York, NY: MacMillan.

Wegner, D. M., Erber, R., \& Raymond, P. (1991). Transactive memory in close relationships. Journal of Personality and Social Psychology, 61, 923-929.

Weick, K. E., \& Roberts, K. H. (1993). Collective mind in organizations: Heedful interrelating on flight decks. Administrative Science Quarterly, 38, 357-381.

Wenger, E. (1998). Communities of practice, learning, meaning and identity. Cambridge, UK: Cambridge University Press.

*Yoo, Y., \& Kanawattanachai, P. (2001). Developments of transactive memory systems and collective mind in virtual teams. The International Journal of Organizational Analysis, 9, 187-208. 